\title{
Case Report \\ Congenital Hypothyroidism Caused by a PAX8 Gene Mutation Manifested as Sodium/Iodide Symporter Gene Defect
}

\author{
Wakako Jo, ${ }^{1}$ Katsura Ishizu, ${ }^{1}$ Kenji Fujieda, ${ }^{2}$ and Toshihiro Tajima ${ }^{1}$ \\ ${ }^{1}$ Department of Pediatrics, Hokkaido University School of Medicine, N15, W7, Sapporo, Hokkaido 060-8638, Japan \\ ${ }^{2}$ Department of Pediatrics, School of Medicine, Asahikawa Medical College, 2-1-1-1 Midorigaoka Higashi, Asahikawa, \\ Hokkaido 078-8510, Japan
}

Correspondence should be addressed to Toshihiro Tajima, tajeari@med.hokudai.ac.jp

Received 22 June 2009; Accepted 20 September 2009

Academic Editor: Duncan Topliss

Copyright ( $) 2010$ Wakako Jo et al. This is an open access article distributed under the Creative Commons Attribution License, which permits unrestricted use, distribution, and reproduction in any medium, provided the original work is properly cited.

\begin{abstract}
Loss-of-function mutations of the PAX8 gene are considered to mainly cause congenital hypothyroidism $(\mathrm{CH})$ due to thyroid hypoplasia. However, some patients with PAX8 mutation have demonstrated a normal-sized thyroid gland. Here we report a $\mathrm{CH}$ patient caused by a PAX8 mutation, which manifested as iodide transport defect (ITD). Hypothyroidism was detected by neonatal screening and L-thyroxine replacement was started immediately. Although ${ }^{123} \mathrm{I}$ scintigraphy at 5 years of age showed that the thyroid gland was in the normal position and of small size, his iodide trapping was low. The ratio of the saliva/plasma radioactive iodide was low. He did not have goiter; however laboratory findings suggested that he had partial ITD. Gene analyses showed that the sodium/iodide symporter (NIS) gene was normal; instead, a mutation in the PAX8 gene causing R31H substitution was identified. The present report demonstrates that individuals with defective PAX8 can have partial ITD, and thus genetic analysis is useful for differential diagnosis.
\end{abstract}

\section{Introduction}

Congenital hypothyroidism $(\mathrm{CH})$ is the most common congenital endocrine disorder and occurs at rate of 1 in 3000-4000 births [1]. The causes of $\mathrm{CH}$ can be classified into two groups: thyroid developmental defects (thyroid dysgenesis) and inborn errors of thyroid hormone biosynthesis (dyshormonogenesis). Several genes responsible for thyroid dysgenesis have been identified such as TSH $\beta$-subunit, TSH receptor, the Gs $\alpha$-subunit, TTF-1, TTF-2, GLIS3, and PAX8 [2]. Among them, PAX8 is a paired domain transcription factor and is expressed in the developing thyroid, kidney, and several areas of the central nervous system [3]. In addition to its role in normal thyroid development, PAX8 regulates the expression of genes encoding thyroglobulin (TG), thyroid peroxidase (TPO), and the sodium-iodide symporter (NIS) by binding to their promoter regions through its 128-amino acid paired domain $[4,5]$. To date, several mutations of the PAX8 gene have been identified in $\mathrm{CH}$ patients [6-12]. Most of these mutations have caused thyroid dysgenesis; however, some patients with PAX8 mutation have a normalsized thyroid gland $[9,10]$.
Iodide transport defect (ITD) is a rare disorder characterized by an inability of the thyroid to maintain a concentration difference of readily exchangeable iodide between the plasma and the thyroid. Diagnostic criteria for ITD include a variable degree of $\mathrm{CH}$ and goiter, low or absent radioiodide uptake, as determined by thyroid scintigraphy, and low iodide saliva to plasma $(\mathrm{S} / \mathrm{P})$ ratio $[13,14]$. This disease is caused by mutations of the NIS gene [13-17].

Here we report that a patient with a PAX8 mutation showed low iodide S/P ratio. The PAX8 mutation in this patient manifested as $\mathrm{CH}$ due to ITD.

\section{Case Report}

A male infant was born after full-term gestation by normal vaginal delivery from nonconsanguineous parents. His birth weight was $3342 \mathrm{~g}$. The family history revealed no thyroid disease. There were no abnormal physical findings; however, neonatal mass screening using filter paper for congenital hypothyroidism at the age of 6 days showed a high level of thyroid stimulating hormone (TSH) $(62.8 \mathrm{mU} / \mathrm{L}$, normal 
TABLE 1: Laboratory findings in the patient.

\begin{tabular}{lc}
\hline Values of filter paper at neonatal screening & \\
TSH $(\mathrm{mU} / \mathrm{L})($ normal range $0.1 \sim 10)$ & 62.8 \\
Values at the time of the first evaluation $($ Serum) & \\
17 days of age & \\
TSH $(\mathrm{mU} / \mathrm{L})$ (normal range $0.34 \sim 3.5)$ & 202.7 \\
T4 $(\mathrm{nmol} / \mathrm{L})($ normal range $59.2 \sim 161.2)$ & 91.2 \\
T3 $(\mathrm{nmol} / \mathrm{L})($ normal range $1.22 \sim 2.76)$ & 1.88 \\
${ }^{123} \mathrm{I}$ thyroid scan $(\%)^{\mathrm{a}}$ at $1,3,24 \mathrm{~h}$ & $4.8,5.8,2.9$ \\
Saliva/Serum $^{123}$ ratio $^{\mathrm{b}}$ at $2 \mathrm{~h}$ and $4 \mathrm{~h}$ & $4.5,3.8$ \\
\hline Thyroid scan was performed at age of 6 years a, normal above $10 \%-35 \%, \mathrm{~b}$,
\end{tabular} normal above 20 .

$<10 \mathrm{mU} / \mathrm{L})$. The patient was referred to our hospital at the age of 17 days for further evaluation. At that time his body weight was $3950 \mathrm{~g}$. Physical examination did not show any abnormal findings including goiter. Biochemical evaluation revealed that the serum TSH level was $202.7 \mathrm{mU} / \mathrm{L}$, thyroxine, $91.3 \mathrm{nmol} / \mathrm{L}$, and triiodothyronine, $1.88 \mathrm{nmol} / \mathrm{L}$ (Table 1 ). He was treated with levothyroxine (L-T4) at that time. At the age of 5 years, he underwent ${ }^{123}$ I scintigraphy after the discontinuing L-T4 treatment for one month. Although ${ }^{123}$ I scintigraphy showed a normally located thyroid gland, his 1-, 3-, and 24-hour ${ }^{123}$ I uptake values were $4.8 \%, 5.8 \%$, and $2.9 \%$, respectively (normal range, $10 \%-30 \%) .{ }^{123} \mathrm{I} \mathrm{S} / \mathrm{P}$ ratios at 2 and 4 hours were 4.5 and 3.8 , respectively (normal $>20$ ) (Table 1 ). He did not have goiter; however, his diagnosis was considered to be partial ITD based on low thyroidal iodide uptake and low S/P ratio. The patient is currently 23 years old, and he has never developed goiter during follow-up.

\section{Method}

After obtaining written consent from the patient and the patient's parent, genomic DNA was extracted from peripheral blood lymphocytes. The NIS and PAX8 genes were amplified by polymerase chain reaction (PCR) according to previously-described methods $[6,17]$. After PCR amplification, the amplified products were subjected to direct sequencing.

\section{Results}

Analysis of the NIS gene revealed no nucleotide changes in the coding region nor in the exon-intron boundaries. Upon analysis of the PAX8 gene, we identified the patient washeterozygous for an arginine (CGC)-to-histidine (CAC) substitution at codon $31(\mathrm{R} 31 \mathrm{H})$, which was previously reported in a patient with $\mathrm{CH}$ [6] (Figure 1).

\section{Discussion}

In the present study, we reported a Japanese patient with $\mathrm{R} 31 \mathrm{H}$ substitution in the PAX8 protein. Since the arginine at residue 31 is located in the paired domain in the PAX8

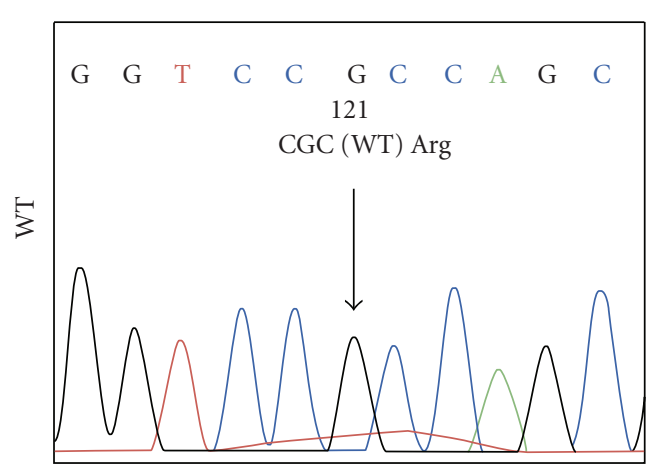

(a)

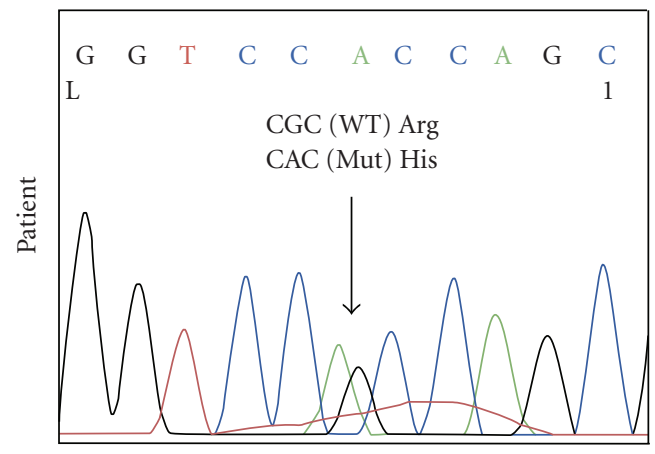

(b)

Figure 1: Sequence analysis demonstrated a C to A transition in the patient. This change substitutes histidine for arginine at residue 31 in the paired domain denoted by the arrow. WT: wild-type.

protein and is conserved among species, this amino acid substitution is thought to impair its DNA-binding activity, resulting in loss of function. It is of interest that a mutation at this residue was previously found in one Italian patient and one Japanese patient $[6,7]$. These two patients were diagnosed as having thyroid hypoplasia as determined by ultrasonographic examination. We also identified $\mathrm{R} 31 \mathrm{H}$ in another Japanese $\mathrm{CH}$ patient who had hypoplastic thyroid (unpublished data). To determine whether or not substitution of this arginine is frequent among Japanese patients with $\mathrm{CH}$, further analysis is required.

Defective mutations of the PAX8 gene have been considered to mainly cause thyroid hypoplasia. However, clinical heterogeneity has been observed among patients and even in the same family $[9,10]$. One patient who had S54G substitution in of the PAX8 protein had organification defect and a normal-sized thyroid [10]. Since PAX8 plays a critical role in TPO expression during thyroid development $[2,4]$, impaired TPO gene expression due to PAX8 dysfunction may have led to organification defect in that patient. In this context, it may be possible that NIS expression is affected by mutations of the PAX8 gene, because a PAX8 binding site was found in the far-upstream enhancer region of the human NIS gene and PAX8 was required for activation of NIS gene expression in the thyroid [18]. As mentioned earlier, the hallmarks of ITD are markedly reduced or absent thyroidal uptake of radioiodide and reduced iodide $\mathrm{S} / \mathrm{P}$ ratio. Absence 
of thyroidal iodide uptake is a typical feature of thyroid agenesis, and thus diagnosis is erroneously assigned to some patients with iodide trapping defect, especially when goiter was not present. Szinnai et al. [14] summarized the clinical features, laboratory findings, and mutations of the NIS gene in patients with ITD. Among these 31 patients, radioiodide uptake ranged from $<1 \%$ to $4.8 \%$ and the iodide $\mathrm{S} / \mathrm{P}$ ratio ranged from 0.94 to 5.2. Regarding goiter, 18 patients developed goiter and its diagnosis was made at a median age of 11 years. In our patient, the value of radioiodide uptake was higher than that in previously reported patients. However, the iodide S/P ratio in our patient was low. An iodide $\mathrm{S} / \mathrm{P}$ ratio in the vicinity of 1 is considered to be the consequence of complete ITD while an iodide $\mathrm{S} / \mathrm{P}$ ratio of up to 20 is considered to represent partial ITD [13]. Therefore, we initially speculated that the cause of $\mathrm{CH}$ in our patient was partial ITD due to defective NIS. However, sequence analysis showed that the NIS gene was normal; instead a mutation causing $\mathrm{R} 31 \mathrm{H}$ in the PAX8 protein was found. As mentioned earlier, PAX8 gene expression during the fetal period is observed in the developing thyroid and kidney during human development [3]; however, its expression in salivary glands has not been examined. It is tempting to speculate that PAX8 is expressed and enhances NIS gene expression during embryogenesis in the human salivary glands similar to in the thyroid gland. Thus, PAX8 mutation may impair NIS function not only in the thyroid but also in the salivary glands. This possibility must be studied further.

In conclusion, we reported a patient with a mutation causing $\mathrm{R} 31 \mathrm{H}$ substitution in the PAX8 protein, which manifested as partial ITD.

\section{References}

[1] D. A. Fisher, J. H. Dussault, T. P. Foley Jr., et al., "Screening for congenital hypothyroidismml: results of screening one million North American infants," Journal of Pediatrics, vol. 94, no. 5, pp. 700-705, 1979.

[2] G. Van Vliet, "Development of the thyroid gland: lessons from congenitally hypothyroid mice and men," Clinical Genetics, vol. 63, no. 6, pp. 445-455, 2003.

[3] A. Poleev, H. Fickenscher, S. Mundlos, et al., "PAX8, a human paired box gene: isolation and expression in developing thyroid, kidney and Wilms' tumors," Development, vol. 116, no. 3, pp. 611-623, 1992.

[4] M. Zannini, H. Francis-Lang, D. Plachov, and R. Di Lauro, "Pax-8, a paired domain-containing protein, binds to a sequence overlapping the recognition site of a homeodomain and activates transcription from two thyroid-specific promoters," Molecular and Cellular Biology, vol. 12, no. 9, pp. 42304241, 1992.

[5] M. Ohno, M. Zannini, O. Levy, N. Carrasco, and R. Di Lauro, "The paired-domain transcription factor Pax8 binds to the upstream enhancer of the rat sodium/iodide symporter gene and participates in both thyroid-specific and cyclic-AMPdependent transcription," Molecular and Cellular Biology, vol. 19, no. 3, pp. 2051-2060, 1999.

[6] P. E. Macchia, P. Lapi, H. Krude, et al., "PAX8 mutations associated with congenital hypothyroidism caused by thyroid dysgenesis," Nature Genetics, vol. 19, no. 1, pp. 83-86, 1998.
[7] M. Komatsu, T. Takahashi, I. Takahashi, M. Nakamura, and G. Takada, "Thyroid dysgenesis caused by PAX8 mutation: the hypermutability with CpG dinucleotides at codon 31," Journal of Pediatrics, vol. 139, no. 4, pp. 597-599, 2001.

[8] T. Congdon, L. Q. Nguyen, C. R. Nogueira, R. L. Habiby, G. Medeiros-Neto, and P. Kopp, "A novel mutation (Q40P) in PAX8 associated with congenital hypothyroidism and thyroid hypoplasia: evidence for phenotypic variability in mother and child," The Journal of Clinical Endocrinology \& Metabolism, vol. 86, no. 8, pp. 3962-3967, 2001.

[9] L. de Sanctis, A. Corrias, D. Romagnolo, et al., "Familial PAX8 small deletion (c.989_992delACCC) associated with extreme phenotype variability," The Journal of Clinical Endocrinology \& Metabolism, vol. 89, no. 11, pp. 5669-5674, 2004.

[10] L. Meeus, B. Gilbert, C. Rydlewski, et al., "Characterization of a novel loss of function mutation of PAX8 in a familial case of congenital hypothyroidism with in-place, normal-sized thyroid," The Journal of Clinical Endocrinology \& Metabolism, vol. 89, no. 9, pp. 4285-4291, 2004.

[11] M. Tonacchera, M. E. Banco, L. Montanelli, et al., "Genetic analysis of the PAX8 gene in children with congenital hypothyroidism and dysgenetic or eutopic thyroid glands: identification of a novel sequence variant," Clinical Endocrinology, vol. 67, no. 1, pp. 34-40, 2007.

[12] S. A. Esperante, C. M. Rivolta, L. Miravalle, et al., "Identification and characterization of four PAX8 rare sequence variants (p.T225M, p.L233L, p.G336S and p.A439A) in patients with congenital hypothyroidism and dysgenetic thyroid glands," Clinical Endocrinology, vol. 68, no. 5, pp. 828-835, 2008.

[13] J. Pohlenz and S. Refetoff, "Mutations in the sodium/iodide symporter (NIS) gene as a cause for iodide transport defects and congenital hypothyroidism," Biochimie, vol. 81, no. 5, pp. 469-476, 1999.

[14] G. Szinnai, S. Kosugi, C. Derrien, et al., "Extending the clinical heterogeneity of iodide transport defect (ITD): a novel mutation $\mathrm{R} 124 \mathrm{H}$ of the sodium/iodide symporter gene and review of genotype-phenotype correlations in ITD," The Journal of Clinical Endocrinology \& Metabolism, vol. 91, no. 4, pp. 1199-1204, 2006.

[15] H. Fujiwara, K. Tatsumi, K. Miki, et al., "Congenital hypothyroidism caused by a mutation in the $\mathrm{Na}+/$-symporter," Nature Genetics, vol. 17, no. 1, pp. 124-125, 1997.

[16] J. Pohlenz, I. M. Rosenthal, R. E. Weiss, S. M. Jhiang, C. Burant, and S. Refetoff, "Congenital hypothyroidism due to mutations in the sodium/iodide symporter. Identification of a nonsense mutation producing a downstream cryptic $3^{\prime}$ splice site," Journal of Clinical Investigation, vol. 101, no. 5, pp. 10281035, 1998.

[17] S. Kosugi, Y. Sato, A. Matsuda, et al., "High prevalence of $\mathrm{T} 354 \mathrm{P}$ sodium/iodide symporter gene mutation in Japanese patients with iodide transport defect who have heterogeneous clinical pictures," The Journal of Clinical Endocrinology \& Metabolism, vol. 83, no. 11, pp. 4123-4129, 1998.

[18] K. Taki, T. Kogai, Y. Kanamoto, J. M. Hershman, and G. A. Brent, "A thyroid-specific far-upstream enhancer in the human sodium/iodide symporter gene requires Pax-8 binding and cyclic adenosine $3^{\prime}, 5^{\prime}$-monophosphate response element-like sequence binding proteins for full activity and is differentially regulated in normal and thyroid cancer cells," Molecular Endocrinology, vol. 16, no. 10, pp. 2266-2282, 2002. 


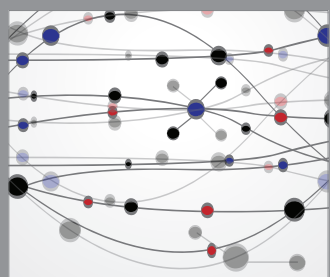

The Scientific World Journal
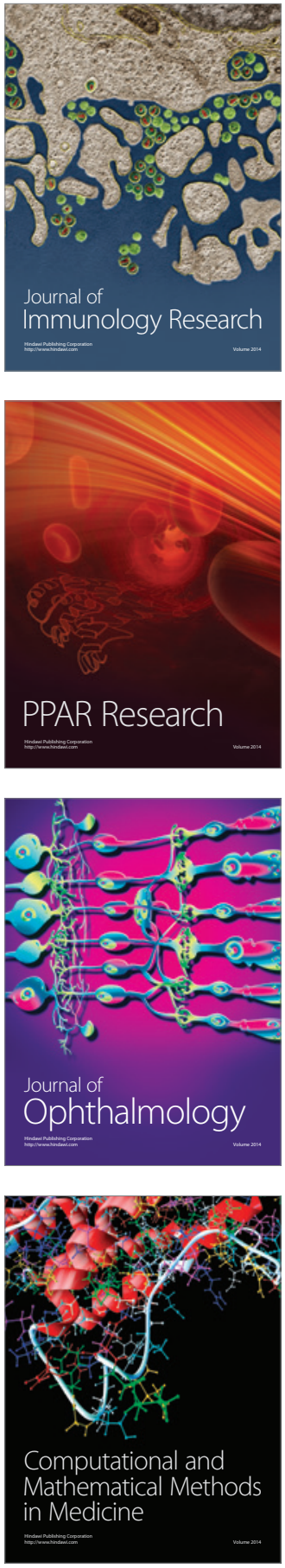

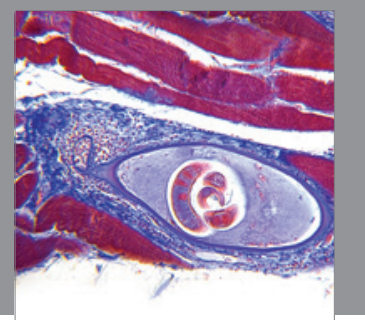

Gastroenterology

Research and Practice
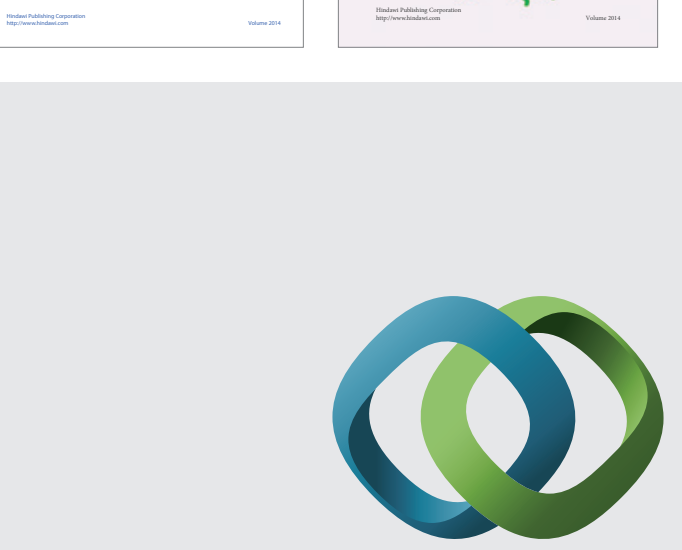

\section{Hindawi}

Submit your manuscripts at

http://www.hindawi.com
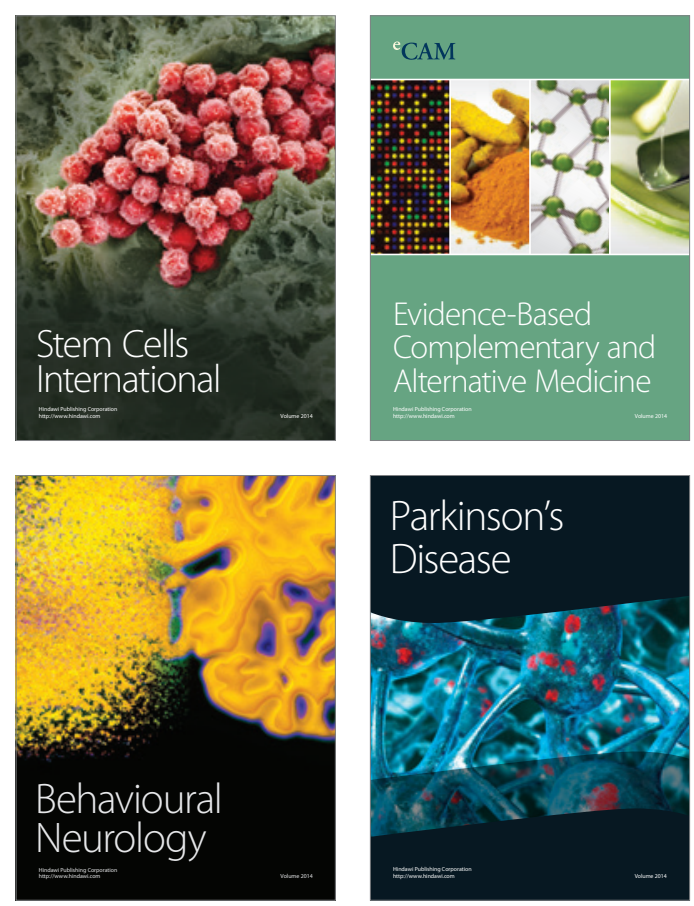

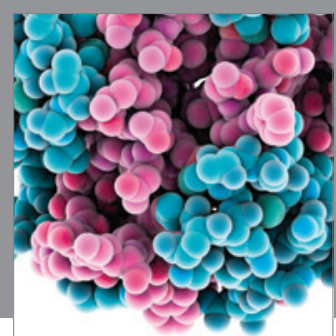

Journal of
Diabetes Research

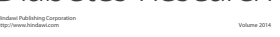

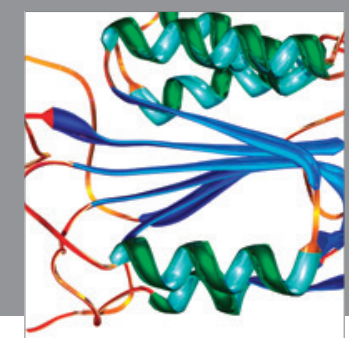

Disease Markers
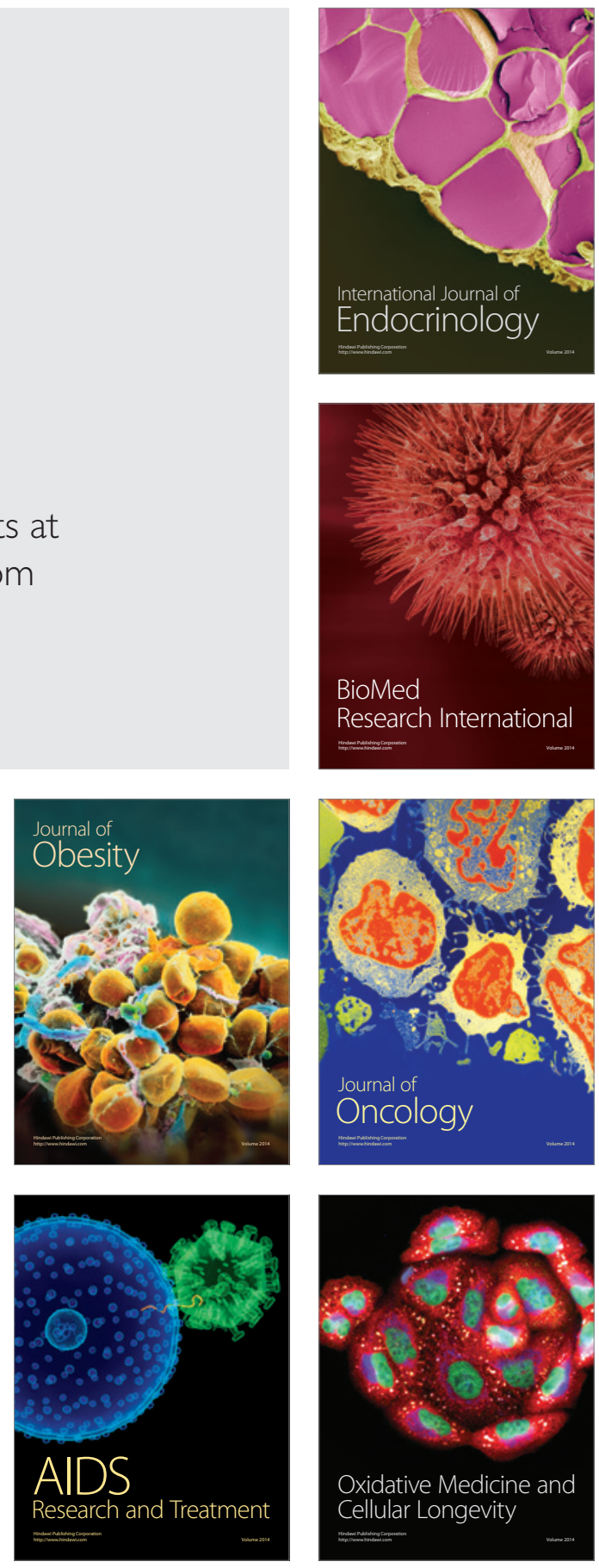